- Practice-based research is likely to produce results of greatest relevance to GDPs.

- Training a new breed of practitioner-researcher could assist academic colleagues in producing better quality research and clinical guidelines.

- Solving the 'swampy lowland' problems of practice requires more research based on an interpretive, qualitative methodology.

\title{
The reflective practitioner - another way of looking at primary dental care
}

\author{
A. Toy ${ }^{1}$
}

Research outcomes are of no value if the methods from which they are derived have no legitimacy. The methods must justify our confidence. ${ }^{1}$

This opinion article seeks to identify why problems arise when research derived from an academic or secondary care situation is applied to general dental practice. The article also offers an additional approach to clinical research through the creation of a new breed of practitioner-researchers, trained to help create guidelines of greater legitimacy to primary dental care. In essence, research intended for primary dental care must reflect the messy world of everyday practice as opposed to the relatively uncluttered high ground of academia.

\section{INTRODUCTION}

The opinion article 'Does the dental profession know how to care for the primary dentition?'2 raises a number of interesting issues about the role of expert clinical guidelines and the problem with much current clinical research in the field of primary dental care.

The article highlighted the problems of applying dental school thinking into the primary care situation. The British Society of Paediatric Dentistry (BSPD) guidelines on the restoration of carious primary molars advocate the use of stainless steel crowns. These guidelines were no doubt developed in good faith by their members, with the sole intention of helping the caries-ridden children of the UK. However, in the world of the general dental services, the article's authors found a large number of experienced practitioners had inde-

\footnotetext{
1*Partner, Gorse Covert Dental Practice and part-time tutor in Clinical Education, University of Nottingham. ${ }^{*}$ Correspondence to Dr Andy Toy, Gorse Covert Dental Practice, 34 Maxwell Drive, Loughborough LE11 4RZ. Email:andy.toy@talk21.com
}

\section{Refereed Paper}

Received 22.01.04; Accepted 26.01.04

DOI: $10.1038 /$ sj.bdj.4811969

๑ British Dental Journal 2005; 198: 67-68 pendently of each other created their own set of 'guidelines'. In précis, they believe it is usually better to leave the untreated carious tooth to exfoliate rather than treat with a stainless steel crown. A number of reasons were given, for example psychological trauma to the child, impact on the family, time and financial constraints. There was no scientific research to back this decision, only their clinical intuition based on years of continuing care experience with hundreds if not thousands of children.

We should not heap blame on the conscientious academics of the BSPD. As Milsom et al. ${ }^{2}$ point out, the provision of a stainless steel crown is probably very reasonable in the context of the academic dental school clinic. Clearly, however, a large number of practitioners felt the BSPD guidelines did not fit with the context of their practice.

This difference between the BSPD guidelines and the reality of general dental practice leads me to the following observations:

1. Conclusions created from research that ignores reference to the practice context are of questionable legitimacy. ${ }^{1}$ Legitimacy can be defined as the degree to which the research findings reflect the reality under study. Researchers need to get closer to the practice setting and use methods of research that have greater legitimacy to it.

2. Practitioners are unlikely to adopt guidelines that do not 'fit' with their practice experience.

3. In this instance, practitioners appear to have come to the 'right' conclusion based on their own individual clinical experience. However, relying on this haphazard process alone could be dangerous at worst. At best, the profession misses out on a lot of new knowledge that a legitimate research process could uncover.

4. There could be a great deal of value in creating practitioner-researchers to tackle the issues of primary dental care.

To find the reasons for these problems it is necessary to understand a little of the history behind the development of today's professional. In his book The Reflective Practitioner, ${ }^{3}$ Donald Schön draws on his many years of study to describe the way a wide range of professionals work in practice, and contrasts it with the way they are trained in academic establishments. Schön 
says professionals are 'inherently artistic' in their decision-making. They combine 'facts' derived from research with their own experience and apply them to the unique situation they are dealing with at the time (in our case an individual patient). In general dental practice the decisions we make every minute of our working day are usually intuitive, a mixture of both the science and the art of dentistry.

During the late nineteenth century, the training of professionals was placed within the domain of the universities. The dominant paradigm at this time was positivism and the reductionistic scientific method. Put very, very simply, this paradigm says:

1 . The world is best understood by reducing it to smaller and smaller parts, deliberately isolating each part from another eliminates 'contamination' of data

2. Data should be quantitative; and

3. There is an 'objective truth' out there, to be gradually revealed by filling in the gaps in our knowledge. ${ }^{4}$

Unfortunately, in practice the professional does not work in a world full of small, isolated parts. For example, it is not enough to understand the action of acids on enamel to prevent decay. The decayed enamel we deal with in primary dental care comes attached to a highly complex series of components called a patient. To achieve optimum care the skilled professional must apply his/her knowledge and experience to each individual patient's unique circumstances. In this example, care may be: restore, leave, apply fluoride, educate etc etc. This decision making is what Schön describes as 'professional artistry?

I observe that the vast majority of the research in dentistry today still follows the reductionist approach with its emphasis on quantitative data. Schön comments that this research produces solutions for the problems of the 'hard, high ground'. Therefore, it is inherently difficult to apply its results to his 'swampy lowlands' of professional practice. I would like to make clear at this point that I believe reductionist, quantitative research plays a very important part in primary dental care. However, to extract most value from it we have to understand its limitations as well as its strengths.
There is another way of looking at the world; the 'naturalistic' paradigm. ${ }^{4}$ Again, very simply the world can also be understood by:

1. Seeking to understand it as a whole

2. Studying the relationships between its component parts, or their context; and

3. Taking the stance that there is not one 'objective truth' out there waiting to be revealed, but each individual holds their own version of reality - a 'subjective truth'.

This paradigm requires more qualitative methods of inquiry. This is the philosophical basis of much social science research, developed throughout the twentieth century with its own myriad methodologies.

Social science seeks to understand the social world, the ways human beings act and interact. As a human being, the researcher cannot stand apart from the research process, but is integral to it. Many social researchers attempt to reveal the thoughts and feelings as well as the behaviour associated with the area under study. They must learn to take a 'critical' stance. ${ }^{5}$ The 'critical' researcher attempts an allencompassing viewpoint of a situation including their own opinions and biases; sitting on their own shoulder and looking in, as it were. Finally, 'critical' researchers are always guided by the way their research relates to practice. ${ }^{6}$

Data is gathered and analysed in a well structured and rigorous process of reflection. As data is more qualitative in nature, the mode of analysis is interpretative rather than statistical. (It can be argued that even the cleanest statistical data ultimately needs interpretation.) In the qualitative world, the 'critical' researcher seeks to create understanding by describing and interpreting all the relevant factors involved in an issue and how they relate to each other.

Like quantitative research, there are limitations to qualitative methodologies. One method should not be seen to be superior to another - merely one will be more appropriate to the study of a given situation than another. ${ }^{1}$

The author contends that adopting some of the more qualitative methods of social scientists in primary dental care research would gain valuable insight on some of the more complex, human related issues of our field. However, in creating practitionerresearchers, it is not enough to adopt the techniques alone; there also needs to be an understanding of the philosophical background of this paradigm. In the author's experience, this understanding produces researchers who are more 'critical' in their approach; more rigorous in their interpretation; more complete in their reflection the true 'reflective practitioner'.

Kincheloe $^{5}$ elaborates: '(critical researchers) are unlimited in their adaptability; they can perceive holistically; they can link apparently disparate aspects of the social world and are capable of understanding; they can synthesise information, generate interpretations, explore the atypical situation. (Practitioner)-researchers can revolutionise professional practice by viewing themselves as potentially the most sophisticated research instruments available.'

With the advent of Options for Change, it is possible that a number of fellow practitioners will be able to break free from the old treadmill of 'drill, fill and bill' and combine qualitative research skills with their experience of primary dental care. Using such a group of reflective practitioners, it should be possible to create a body of research which, combined with the work of our academic colleagues, will get to grips with some of the swampy lowland problems of primary dental care. As a result, we may have the opportunity to create 'legitimate' clinical guidelines - patient-centred and relevant to our world.

1. Newman, Benz. Qualitative-quantitative research Methodology, Exploring the Interactive Continuum. South IIlinois University Press Carbondale III 1998. p27

2. Milsom K M, Tickle M, King D. Does the dental profession know how to care for the primary dentition? Br Dent J 2003; 195: 301-303.

3. Schön D. The reflective practitioner: how professionals think in action. Aldershot: Ashgate Publishing 1991.

4. Cohen, Manion. Research methods in Education. 4th ed. London: Routledge 1994.

5. Kincheloe J. Teachers as researchers: qualitative inquiry as a path to empowerment. London: Falmer Press 1991.

6. Carr, K. Becoming critical. London: Falmer Press 1986. 